\title{
Efeitos aversivos das práticas de avaliação da aprendizagem escolar
}

- Sérgio Antônio da Silva Leite*

Samantha Kager**

\section{Resumo}

0 presente artigo tem como objetivo discutir os efeitos aversivos das práticas tradicionais de avaliação da aprendizagem escolar. Baseando-se em dados de pesquisa coletados através de entrevistas com jovens do último ano do ensino médio, organizaram-se núcleos temáticos que permitiram identificar os aspectos aversivos do processo de avaliação da aprendizagem escolar, bem como os seus efeitos nos alunos. Na discussão, aponta-se como alternativa o processo de avaliação diagnóstica para o trabalho pedagógico dos professores.

Palavras-chave: Avaliação escolar. Afetividade. Mediação pedagógica.

Ensino-aprendizagem.

\section{Aversive effects of the school evaluation practices Abstract}

This paper aims to discuss the effects which are averse to the traditional evaluation practices at schools. Based on research data, collected by interviews with high school students, thematic nucleus were formed to allow the identification of aversive aspects of the evaluation school process and its effects on the pupils. The discussion pointed out the concept of diagnostic evaluation as an alternate process for the teachers' work in class.

Keywords: School evaluation. Affection. Pedagogic mediation. Teaching-learning.

\section{Efectos aversivos de las prácticas de evaluación del aprendizaje escolar Resumen}

El presente artículo discute los efectos aversivos de las prácticas tradicionales de evaluación del aprendizaje escolar. Con base en dados de investigación, colectados a través de entrevistas con estudiantes de bachillerato, fueron definidos núcleos temáticos que permiten identificar los aspectos aversivos del proceso de evaluación escolar, como también

\footnotetext{
* Doutor em Psicologia, USP. Professor da Unicamp. E-mail: sasleite@uol.com.br

** Pedagoga, Unicamp; Professora da rede de ensino municipal de Holambra (SP). E-mail:
} 
sus efectos en los alumnos. En la discusión, se apunta el proceso de evaluación diagnóstica como alternativa para el trabajo pedagógico del maestro en la escuela.

Palabras clave: Evaluación escolar. Afectividad. Mediación pedagógica. Enseñanza - aprendizaje.

\section{Introdução}

0 presente artigo tem como objetivo identificar e analisar as possiveis relações entre as práticas de avaliação da aprendizagem e os seus efeitos aversivos na vida escolar, presente e futura, de alunos. Baseando-se em dados de pesquisa (KAGER, 2006), assume-se que a avaliação é parte do processo da mediação pedagógica do professor que envolve, também, aspectos afetivos, não se restringindo apenas à dimensão cognitiva.

\section{Sobre a avaliação da aprendizagem escolar}

As práticas de avaliação da aprendizagem escolar, predominantes em nosso meio, ainda se dão a partir de um modelo teórico tradicional, que concebe a educação como um mecanismo de manutenção e reprodução das condições sociais.

De acordo com Freitas (2003), a lógica da avaliação não é independente da lógica da escola; ao contrário, ela é produto de uma escola que se separou da vida e das práticas sociais. Como consequência, o autoritarismo é o elemento necessário para a garantia deste modelo social e, dai, a prática da avaliação manifestar-se autoritária. Esta concepção da avaliação da aprendizagem escolar reflete, pois, uma pedagogia que, por sua vez, está a serviço de um modelo dominante que pode ser identificado como liberal conservador.

Para Luckesi (1984), este modelo produziu três pedagogias distintas, mas com um objetivo em comum: manutenção das condições sociais. Assim se apresentam a pedagogia tradicional, a pedagogia renovada ou escolanovista e a pedagogia tecnicista. No entanto, o mesmo autor também aponta três modelos pedagógicos que se desenvolveram como antíteses aos modelos pedagógicos conservadores: a pedagogia libertadora de Paulo Freire, a pedagogia libertária e a pedagogia dos conteúdos socio-culturais de Dermeval Saviani.

Esses dois grupos de pedagogias - tradicionais e emancipadoras - representam concepções antagônicas. 0 primeiro grupo está preocupado com a reprodução e conservação da sociedade, propondo práticas autoritárias de avaliação. 0 segundo grupo assume uma perspectiva de transformação social, objetivo com o qual a educação formal pode contribuir, incluindo práticas de avaliação visando à autonomia do educando. 
Ainda segundo Luckesi (1984, p. 9): "A avaliação é um julgamento de valor sobre manifestações relevantes da realidade, tendo em vista uma tomada de decisão". Ou seja, avaliar implica a emissão de julgamentos de valores, a partir de dados coletados, visando a uma tomada de decisão. Na prática escolar, qualquer desses elementos pode ser perpassado por concepções autoritárias. Porém, o componente da avaliação mais sensivel à questão do poder é o terceiro: a tomada de decisão.

0 modelo tradicional da avaliação escolar define a classificação de indivíduos como a principal função do ato de avaliar. Neste sentido, o julgamento de valor visa a classificar o indivíduo, segundo um padrão determinado. Ele poderá ser classificado, por exemplo, através de notas ou conceitos, situando-se entre os melhores ou os piores. Tais práticas contribuiram para produzir muitas consequências negativas, entre elas o preconceito e o estigma. Nesta perspectiva, a avaliação classificatória pode tornar-se um instrumento autoritário e frenador do desenvolvimento escolar para muitos alunos.

Outro uso autoritário da avaliação tradicional é a sua transformação em mecanismo disciplinador de condutas sociais. Uma prática frequente no meio escolar é a utilização do poder e do veredicto da avaliação para ameaçar os alunos. Como aponta Luckesi (1984, p. 12): "De instrumento diagnóstico para o crescimento, a avaliação passa a ser um instrumento que ameaça e disciplina os alunos pelo medo [...]".

Segundo Freitas (2003, p. 45),

a parte mais dramática e relevante da avaliação se localiza aí, nos subterrâneos onde os juízos de valor ocorrem. Impenetráveis, eles regulam a relação professoraluno e vice-versa. Esse jogo de representações vai construindo imagens e auto-imagens que terminam interagindo com as decisões metodológicas do professor. Os professores, se não forem capacitados para tal, tendem a tratar os alunos conforme os juízos que vão fazendo deles. Aqui começa a ser jogado o destino dos alunos, para o sucesso ou para o fracasso.

Para romper com este modelo, é necessário romper com o modelo de sociedade e com a pedagogia que o traduz. Luckesi (1984) defende que a avaliação educacional escolar assuma o seu verdadeiro papel de instrumento de diagnóstico para 0 crescimento. Para ele, a avaliação só será transformadora e democrática na medida em que as aspirações socializantes da humanidade se traduzam em um modelo pedagógico emancipador e democrático. Para que surjam novas práticas de avaliação dentro de uma sociedade conservadora como a nossa, e no contexto de uma pedagogia autoritária ainda presente em nossas escolas, é necessário que o educador esteja preocupado em redefinir os rumos de toda a sua prática pedagógica. 
0 primeiro passo seria um posicionamento claro e explícito sobre o tipo de sociedade e de cidadão que se pretende formar. Um segundo ponto seria a conversão/ conscientização de cada educador para novos rumos da prática educacional. No entanto, essa conscientização deve ser traduzida em práticas pedagógicas assumidas pelo coletivo dos educadores da escola. 0 último aspecto a ser considerado refere-se ao resgate da avaliação em sua função diagnóstica: mesmo numa sociedade produtora de exclusão social, é possivel rever e alterar os rumos das práticas tradicionais de avaliação. Para isso, o professor deve estar comprometido com uma escola inclusiva, que esteja preocupada com o crescimento e o desenvolvimento integral dos alunos.

A avaliação diagnóstica pode representar uma alternativa viável visto que, nesta perspectiva, 0 ato de avaliar implica decisões sempre a favor do aluno: deve representar um momento de reflexão, sendo os seus resultados utilizados no sentido de rever e alterar as condições de ensino, visando ao aprimoramento do processo de apropriação do conhecimento pelo aluno. Para isso, a escola deve ser um espaço constante de confronto de ideias, resistindo ao contexto de uma sociedade conservadora e de uma pedagogia autoritária.

\section{Sobre o papel da afetividade na avaliação da aprendizagem escolar}

Concepções teóricas mais recentes, como a histórico-cultural, marcadas pela ênfase nos determinantes culturais, históricos e sociais da condição humana, têm possibilitado uma nova leitura sobre as relações entre as dimensões afetivas e cognitivas no ser humano, no sentido de buscar uma visão integradora.

De acordo com essas ideias, entende-se que a relação sujeito-objeto é marcada pela inter-relação entre os aspectos cognitivos e afetivos. Isto ressalta a importância das decisões pedagógicas assumidas pelo professor, pois elas estarão mediando a futura relação que se estabelece entre o aluno e os diversos objetos do conhecimento envolvidos. Assume-se que o sucesso da aprendizagem escolar dependerá, em grande parte, da qualidade da mediação pedagógica do professor: ressalve-se, no entanto, que a qualidade desta mediação, que se estabelece entre sujeito (aluno) e objeto (conteúdos escolares), é, também, de natureza afetiva.

No presente trabalho, buscou-se a contribuição teórica de autores, como Wallon (1968, 1971, 1978) e Vygotsky (1984), que contribuíram para a discussão da relevância da dimensão afetiva na constituição do sujeito e na construção do conhecimento.

De acordo com Galvão (2001), Wallon admitiu que o homem é determinado fisiológica e socialmente, sujeito, portanto, de uma dupla história: a de suas disposições internas e a das situações externas que encontra ao longo de sua existência. De acordo com Wallon, o biológico, que é mais determinante no início da vida, vai, progressivamente, cedendo espaço de determinação ao social. 
Ainda segundo a autora (GALVÃO, 2001), Wallon diferencia os conceitos de afetividade e emoção: as emoções são reações organizadas que se manifestam sob o comando do sistema nervoso central; isto significa que estão vinculadas a componentes orgânicos, não descartando sua caracterização enquanto estado subjetivo. São, portanto, acompanhadas "de modificações visiveis do exterior, expressivas, que são responsáveis pelo seu caráter altamente contagioso e por seu poder mobilizador do meio humano" (GALVÃO, 2001, p. 62).

A afetividade, por sua vez, tem uma concepção mais ampla, envolvendo uma gama maior de manifestações que envolvem sentimentos (origem psicológica) e emoção (origem biológica). Ela aparece num período mais tardio no desenvolvimento da criança, quando surgem os elementos simbólicos, destacando-se a linguagem.

Vygotsky (1984), por sua vez, introduz um conceito fundamental para a aprendizagem e para o desenvolvimento: a mediação. É a partir de um intenso processo de interação com o meio social, através da mediação feita pelo outro, que se dá a apropriação dos bens culturais. Esse complexo processo resulta no desenvolvimento. Ou seja, o desenvolvimento do psiquismo humano é sempre mediado por outras pessoas do grupo social que indicam, delimitam e atribuem significados ao comportamento do indivíduo. São essas interferências que permitem aos indivíduos tomarem posse do patrimônio histórico e da cultura de seu grupo.

Desde o nascimento, a criança tem com o mundo uma relação mediada pelo outro e pela linguagem. Aos poucos, ela aprende a falar e passa a utilizar a própria linguagem para regular suas ações, conferir sentido aos objetos culturais. É na sua relação com o outro que a criança vai-se apropriando das significações socialmente construídas. Assim, é o grupo social que, por meio da linguagem e das significações, possibilita o acesso a formas culturais de perceber e estruturar a realidade.

Dessa forma, a abordagem histórico-cultural considera que o processo de desenvolvimento vai do social para o individual, ou seja, as nossas maneiras de pensar e agir são resultado da apropriação de formas culturais de ação e de pensamento.

Vygotsky (1984) assumiu uma perspectiva de desenvolvimento para as emoções, destacando que não há uma redução ou desaparecimento das mesmas, mas um deslocamento para o plano simbólico, da significação e do sentido.

Ambos, Wallon $(1968,1971,1978)$ e Vygotsky $(1984)$, assumem o caráter social da afetividade e têm uma abordagem de desenvolvimento para ela. Cada um, à sua maneira, demonstra que as manifestações emocionais, de caráter inicialmente orgânico, vão ganhando complexidade, passando a atuar no universo simbólico. Assim, ampliam-se as formas de manifestações, constituindo os fenômenos afetivos. 
Esses autores defendem a intima relação que há entre o ambiente cultural/social e os processos afetivos e cognitivos, além de afirmarem que ambos inter-relacionam-se e influenciam-se mutuamente.

Diante do exposto, evidencia-se a presença contínua da afetividade nas interações sociais, além da sua influência nos processos de desenvolvimento cognitivo. Nesse sentido, pode-se pressupor que

[...] as interações que ocorrem no contexto escolar também são marcadas pela afetividade em todos os seus aspectos. Pode-se supor, também, que a afetividade constitui um fator de grande importância na determinação da natureza das relações que se estabelecem entre os sujeitos (aluno) e os diversos objetos de conhecimento (áreas e conteúdos escolares)" (LEITE; TASSONI, 2002, p. 8).

É importante destacar que a afetividade não se restringe apenas ao contato físico. Conforme a criança vai se desenvolvendo, as trocas afetivas vão ganhando complexidade. Adequar a tarefa às possibilidades do aluno, fornecer meios para que realize a atividade confiando em sua capacidade, demonstrar atenção às suas dificuldades e problemas, são maneiras bastante refinadas de comunicação afetiva. Analisar a questão da afetividade em sala de aula significa, pois, analisar as condições oferecidas para que se estabeleçam os vínculos entre sujeito e objeto. Neste sentido, assume-se que a natureza da experiência afetiva (prazerosa ou aversiva) depende, em grande parte, da qualidade da mediação vivenciada pelo sujeito, na relação com o objeto. De acordo com esses pressupostos, não se pode mais restringir a questão do processo ensino-aprendizagem apenas à dimensão cognitiva, dado que a afetividade também é parte integrante do processo.

Leite (2006) aponta, pelo menos, cinco decisões no planejamento de ensino que, certamente, produzem marcas afetivas e interferem na futura relação que se estabelece entre o aluno e o objeto de conhecimento: escolha dos objetos de ensino; 0 aluno como referência para o início do trabalho pedagógico; a organização dos conteúdos; a escolha dos procedimentos e atividades de ensino; a escolha dos procedimentos de avaliação.

0 presente trabalho tem como foco as decisões pedagógicas que o professor toma em relação às práticas de avaliação, ou seja, aborda, de forma mais detalhada, apenas o último item citado.

Leite e Tassoni (2002, p. 16) apontam que "[...] a avaliação torna-se profundamente aversiva quando o aluno discrimina que as consequências do processo podem ser direcionadas contra ele próprio". De fato, o modelo de avaliação 
adotado em grande parte das escolas tem contribuido com os altos índices de fracasso escolar, representado pela repetência, evasão e, agora, a exclusão intraescolar do aluno. Isso justifica a relevância de trabalhos que revelam os efeitos aversivos do modelo tradicional de avaliação e apontam a necessidade de resgate de uma concepção de avaliação favorável às condições de aprendizagem e desenvolvimento do aluno.

\section{Sobre a pesquisa e seus resultados - os núcleos e subnúcleos}

A pesquisa desenvolvida (KAGER, 2006), de natureza qualitativa, cujos dados são parcialmente apresentados neste artigo, tinha como objetivo identificar e analisar as possiveis relações entre decisões pedagógicas que o professor toma em relação à avaliação da aprendizagem e os efeitos dessas decisões na vida de alunos. Foi parte do projeto de um grupo de pesquisa orientado pelo autor principal deste trabalho.

Os sujeitos participantes da pesquisa foram intencionalmente escolhidos, a partir de dois critérios: estar cursando o $3^{\circ}$ ano do Ensino Médio ou curso pré-vestibular, em escola pública ou privada; ter vivenciado experiências aversivas através de práticas de avaliação, durante a vida escolar.

Dentre todos os sujeitos participantes da pesquisa original, foram escolhidos cinco cujos dados serão aqui apresentados. $S_{1}: 17$ anos, sexo feminino; cursou até a 6 a . série do Ensino Fundamental em escola pública, passando, então, para escola particular; vivenciou experiências aversivas com avaliação nas $1^{\text {a. }}$ e $2^{\text {a }}$. séries do Ensino Médio na disciplina Matemática; na época da coleta dos dados estava no $3^{\circ}$. ano, do Ensino Médio, no periodo matutino. $S_{2}$ : ex-aluno de instituição pública de ensino; 19 anos, sexo masculino; estudou em escolas estaduais e municipais durante toda a vida escolar; vivenciou experiências aversivas com avaliação durante a $3^{\text {a }}$. série do Ensino Fundamental; na época estava fazendo curso prévestibular, no periodo noturno. $\mathrm{S}_{3}$ : ex-aluno de instituição particular de ensino; 18 anos, sexo masculino; estudou até a 8a. série do Ensino Fundamental em escola pública, cursando apenas o Ensino Médio em instituição particular; vivenciou experiências aversivas com avaliação nas $1^{\text {a }}$. e $2^{\text {a }}$. séries do Ensino Médio na disciplina Fisica; na época fazia curso pré-vestibular, no período noturno. $\mathrm{S}_{4}$ : 18 anos, sexo feminino; estudou até a $8^{a}$. série do Ensino Fundamental em escolas públicas, cursando apenas o Ensino Médio em instituição particular de ensino; vivenciou experiências aversivas com avaliação na $2^{\text {a }}$. série do Ensino Médio, na disciplina Química; na época estava cursando o $3^{\circ}$. ano do Ensino Médio, no período matutino. $\mathrm{S}_{5}$ : 18 anos, sexo masculino; estudou somente em escola particular; vivenciou práticas de avaliação aversivas na $5^{\text {a }}$. série do Ensino Fundamental, na disciplina Inglês; estava cursando o $3^{\circ}$ ano do Ensino Médio, no período matutino. 
Os dados foram coletados através de entrevistas gravadas, garantindo-se o sigilo dos sujeitos. A questão central das entrevistas relacionava-se com as práticas aversivas de avaliação vivenciadas e seus efeitos, na vida dos sujeitos. No entanto, foram feitas perguntas sobre os aspectos pedagógicos, com relação às aulas da disciplina que adotou tais práticas de avaliação, e sobre os aspectos afetivos dessas aulas como, por exemplo, a relação do professor com os alunos e a relação do professor com os objetos de ensino, ou seja, os conteúdos da disciplina que ministra.

Após o término de cada entrevista, realizou-se a transcrição da fita, organizando-se os relatos de acordo com os aspectos abordados: aspectos pedagógicos, aspectos afetivos e avaliação. Isso facilitou a realização da etapa seguinte, que foi a análise dos dados obtidos e a criação de núcleos temáticos e subnúcleos, por sujeito. Após o término de todas as entrevistas, realizou-se a etapa final da análise dos dados, com a fusão e organização de um único conjunto de núcleos.

Durante o processo de organização dos núcleos e subnúcleos, procurou-se focar a questão da avaliação, para que não houvesse um desvio do objetivo da pesquisa. Foram selecionadas, nos relatos, as falas que diziam respeito aos possiveis determinantes da aversão em relação à avaliação e seus efeitos na vida dos alunos. Foram identificadas quinze situações ou aspectos que contribuiram para o desenvolvimento de sentimentos aversivos em relação às práticas de avaliação adotadas. A partir dessas situações, os núcleos e subnúcleos foram criados. Segue-se uma síntese dos mesmos.

\section{Núcleo 1 Marcas aversivas}

0 núcleo 1 foi organizado a partir dos relatos verbais relacionados aos efeitos aversivos das práticas de avaliação vivenciadas, que marcaram a vida escolar, presente e futura, dos sujeitos entrevistados.

Este é o maior de todos os núcleos temáticos criados. Os cinco sujeitos participantes relataram, nas entrevistas, sobre as marcas aversivas desenvolvidas pelas práticas de avaliação vivenciadas. Pode-se dizer que este núcleo compreende os relatos mais significativos da presente pesquisa, pois demonstram claramente os efeitos deletérios das práticas de avaliação, na vida dos alunos.

\section{Subnúcleo 1.1 Medo e ansiedade}

Um desses efeitos, que marcaram a vida escolar dos sujeitos entrevistados, é o medo e a ansiedade gerados pelo dia de avaliação. Os sujeitos $\mathrm{S}_{4^{\prime}} \mathrm{S}_{2^{\prime}} \mathrm{S}_{3}$ e $\mathrm{S}_{5}$ revelam como se sentiam:

Quando tinha prova era um terror! Eu tinha até dor de barriga! Nossa, eu ficava muito nervosa, ficava com muito medo! $\left(\mathrm{S}_{4}\right)$.

Dia de avaliação era um terror! A gente ficava morrendo de medo, naquela ansiedade $\left(\mathrm{S}_{2}\right)$. 
Quando a semana de prova se aproximava já ia dando aquele nervoso, aquele medo. Nossa, eu ficava muito ansioso! Era um sentimento horrivel! É ruim até de lembrar! $\left(\mathrm{S}_{3}\right)$.

Eu ficava muito tenso, muito ansioso (em dia de prova). A hora em que a folha da prova chegava na minha mão, era aquela aflição pra ver o que tinha caído $\left(\mathrm{S}_{5}\right)$.

\section{Subnúcleo 1.2 Sentimento de incapacidade}

Outra consequência das práticas aversivas de avaliação é o desenvolvimento de um sentimento de incapacidade que contribui para a baixa autoestima. $\mathrm{S}_{2}$ exemplifica bem isso:

Como eu era criança, eu nem ligava muito pro conteúdo da prova em si. Eu me importava mais com a nota mesmo [...] Eu também queria tirar notas boas como os meus amigos e ficava me sentindo um burro, um incapaz. Era como se eu fosse um anormal ali dentro. 0 diferente, o incompetente. Sabe o que é em nenhuma prova você tirar uma nota azul? É muito frustrante $\left(\mathrm{S}_{2}\right)$.

Assim como $\mathrm{S}_{2}, \mathrm{~S}_{3}$ também comenta sobre o sentimento de incapacidade:

E mesmo na recuperação, que a prova era mais fácil, eu não ia bem, passava raspando. As minhas notas em Física sempre foram 5 , nada mais que isso. Eu me sentia um burro! Um incompetente! $\left(\mathrm{S}_{3}\right)$.

No entanto, através das verbalizações de $\mathrm{S}_{2}$, é possível notar que o sentimento de incapacidade, gerado pela prática de avaliação aversiva, acompanhou-o durante toda a sua vida escolar e, ainda hoje, observam-se os efeitos daquelas experiências negativas:

Esses dias, eu tive simulado e tirei 0,2. Aí eu pensei: 'não tem jeito, eu sou burro mesmo'. E daí volta tudo na minha cabeça, sabe? Qualquer avaliação sempre me faz lembrar daquela época [...] É um trauma mesmo! E nesses casos já volta o desânimo $\left(\mathrm{S}_{2}\right)$.

\section{Subnúcleo 1.3 Perda de motivação para estudar}

Outro efeito relatado pelos participantes é a perda da motivação para estudar e do interesse pela disciplina, além do desânimo, como consequência do insucesso diante do tipo de avaliação adotada:

Chegou uma hora, quando eu vi que não tinha mais jeito, que eu só me ferrava nas provas, que eu desisti! Acabei desanimando. Aí, nem estudar, eu estudava mais [...] E eu tenho a plena consciência de que foi a forma de avaliar dessa professora que causou isso em mim. Era uma coisa sem sentido, sabe? $\left(\mathrm{S}_{2}\right)$. 
0 meu relacionamento com a Física era mal e continua sendo até hoje. Quando você vê que não vai, que mesmo se esforçando não vai, você começa a desanimar, né? [...] chegou uma hora que eu comecei a ficar com raiva da matéria! Parece que não adianta estudar, você não vai conseguir e ponto! $\left(\mathrm{S}_{3}\right)$.

Todo bimestre eu ficava de recuperação [...] As provas eram muito complicadas [...] e o professor ainda esculachava com a minha cara! Chegou uma hora que eu falei pra mim mesma: '[...] não faço mais questão de entender!'. A partir de então, perdi totalmente meu interesse pela Química $\left(\mathrm{S}_{4}\right)$.

No ano seguinte (ao que viveu a experiência negativa) [...] eu passei mas só conseguia a média [...] nada mais que 6 . $E$ isso porque a minha mãe contratou uma professora particular de Inglês. Mas eu odiava essas aulas também! [...] No último bimestre eu me recusei a ter essas aulas de tanto que eu odiava Inglês $\left(\mathrm{S}_{5}\right)$.

\section{Subnúcleo 1.4 Frustração e exclusão}

É possível notar, em algumas falas, a sensação de frustração e de exclusão por repetirem o ano letivo, após vivenciarem a experiência negativa com avaliação:

Quando eu fiz a $3^{\text {a }}$. série pela segunda vez, eu me sentia muito mal dentro da sala de aula. Primeiro porque eu era repetente. Depois porque eu era 'mó' grandão perto do resto dos alunos. Eu me sentia excluido em todos os sentidos. Eu me sentia o burro da sala $\left(\mathrm{S}_{2}\right)$.

Esse ano (quando fez a $5^{a}$. série pela segunda vez) foi horrível pra mim. Todos os meus amigos tinham passado e eu ficava sempre sozinho. Eu vivia brigando com os moleques da minha classe porque eles ficavam me chamando de burro, de repetente. Nossa, foi horrível! $\left(\mathrm{S}_{5}\right)$.

\section{Subnúcleo 1.5 Deterioração da relação sujeito-objeto}

Por fim, as verbalizações revelam um dos efeitos mais graves das práticas de avaliação aversivas: a deterioração da relação sujeito-objeto, ou seja, os alunos, que vivenciaram experiências negativas com avaliação, desenvolveram aversão pela disciplina em que essas práticas de avaliar eram adotadas:

Por causa das avaliações e das aulas desse professor eu passei a não gostar mais de Geometria [...] Eu perdi totalmente o gosto pela Geometria, é uma matéria que, até hoje, eu não consigo mais me interessar [...] É aversão mesmo! [...] Eu odeio Geometria! $\left(\mathrm{S}_{1}\right)$. 
Eu não gosto de Física. Se alguém me perguntar qual é a matéria que eu menos gosto, com certeza vou responder: 'Física!'[...] Da Física, mesmo, desisti, não tenho mais a menor vontade de tentar entender, tanto que vou fazer questão de passar bem longe da área de exatas na faculdade $\left(\mathrm{S}_{3}\right)$.

Depois de tudo que eu passei, eu não posso nem mais ouvir falar em Química. Eu odeio Química! Mas odeio mesmo, com todas as minhas forças. Dá muita raiva quando você se sente vencida, sabe?[...] Hoje, eu não vejo a hora de entrar numa faculdade pra nunca mais ver Química na minha frente $\left(\mathrm{S}_{4}\right)$.

Nunca mais eu consegui gostar de Inglês. E também não tive nenhum professor que fizesse eu me interessar pela matéria de novo [...] Perdi totalmente o interesse por essa matéria [...] Agora eu não faço mais a mínima questão de aprender $\left(\mathrm{S}_{5}\right)$.

\section{Núcleo 2 Controle de corpos}

Este núcleo de significação caracteriza-se pelos relatos referentes às posturas de professores, diretores e auxiliares, diante dos alunos, no momento da avaliação, demonstrando grande preocupação com o controle das condições físicas e os efeitos aversivos dessas medidas.

Através dos relatos é possível notar a extrema preocupação, por parte dos educadores, com o controle dos alunos em dia de avaliação. As medidas tomadas acabam por transformar essa situação em um ritual desgastante e ameaçador, como conta $\mathrm{S}_{1}$ :

Quando tinha avaliação era um ritual! Neste dia $01^{\circ}{ }^{\circ}, 02^{\circ}$. e $03^{\circ}$. colegial faziam prova da mesma matéria, no mesmo horário. Era tudo junto! As três classes iam pro anfiteatro. Antes da porta do anfiteatro ser aberta, tínhamos que ficar em fila, intercalando um aluno do $1^{\circ}$., um do $2^{\circ}$. e um do $3^{\circ}$ para evitar conversas. A porta abria às sete horas da manhã e aí cada aluno tinha que sentar num lugar pré-determinado, o diretor distribuía um mapa antes para todos os alunos. A gente tinha que entrar com a manga da blusa erguida e só com o lápis, a caneta e a borracha na mão. Depois que todo mundo tivesse sentado, o diretor passava distribuindo uma folha de questões e a outra para as respostas. Lá também era tudo intercalado para que dois alunos da mesma classe não ficassem perto. Nem com esforço a gente conseguia colar! Na sala ficava o diretor e uma monitora e durante a prova eles ficavam circulando entre as carteiras. Se caía qualquer coisa no chão, borracha, lápis, qualquer coisa, a gente tinha que chamar algum dos dois para eles pegarem. A gente não podia dar um 'piu', nem mascar chiclete! Eram exatamente 50 minutos de prova, nem um a 
mais! Se a gente tivesse na metade de uma questão e tivesse dado o tempo, o diretor vinha e arrancava a prova da nossa mão! Se a gente chegava um minuto atrasado também não podia mais entrar e ficava com zero na prova [...] Parecia uma ditadura!

Outra medida, adotada pelos professores em dia de prova, para evitar a cola pelos alunos, era o controle visual, na medida em que eles circulavam pela classe:

$\mathrm{Na}$ hora da prova, a classe tinha que ficar num silêncio total e ela (professora) ficava circulando, pra ninguém se mover mesmo. A gente tinha muito medo dela e aí nem olhávamos pro lado pra não correr o risco dela arrancar a prova da gente $\left(\mathrm{S}_{2}\right)$.

\section{Núcleo $3 \mathrm{~A}$ prova como armadilha}

0 núcleo 3 inclui os relatos verbais que retratam a avaliação como uma armadiIha, criada pelos professores, na medida em que cobram, intencionalmente, na prova, conhecimentos mais complexos, que não se relacionam com as práticas desenvolvidas na sala de aula.

Os relatos demonstram sentimento de revolta diante das provas, que exigiam resolução de exercícios mais complexos que os trabalhados em sala de aula, revelando-se verdadeiras armadilhas, com situações imprevisiveis aos alunos.

A fala de $S_{1}$ revela esse sentimento:

[...] Sabe o que é você estudar um monte para uma prova e na hora não conseguir fazer nada? Você não tem noção, os exercícios eram os mais difíceis que você pode imaginar. Dava raiva! [...] parecia que ele queria ferrar mesmo.

Esse sentimento de revolta também é percebido nas verbalizações de S3 e S5:

Uma semana antes da prova, a gente falava: 'Explica a matéria que vai cair, pra gente poder estudar. Dá o mesmo tipo de exercício que você vai dar na prova, pra gente ter uma noção de como ela vai ser'. Daí, ele (professor) passava uns exercicios na lousa, explicava [...] Só que chegava na hora da prova e caía umas coisas totalmente diferentes! Uns exercícios bem mais dificeis! [...] até os alunos mais inteligentes se ferravam nas provas dele [...] Ele só podia estar querendo ferrar com a classe [...] Não tem outra explicação $\left(\mathrm{S}_{3}\right)$.

$\mathrm{Na}$ hora da prova eu sempre me ferrava porque nos exercicios do livro, a gente só precisava preencher lacunas no meio da frase...era só colocar o verbo...Mas na hora da prova tava tudo misturado: passado, presente e futuro, dai a 
gente tinha que entender a frase pra completar e eu não conseguia entender nada $\left(\mathrm{S}_{5}\right)$.

$\mathrm{S}_{3}$ deixa claro, em seus relatos verbais, a idéia da prova como armadilha:

"A prova dele não tinha nada a ver com as aulas dele".

\section{Núcleo 4 Ritmo da semana de provas}

Neste núcleo de significação é possivel observar, através das falas dos sujeitos entrevistados, relatos que descrevem a sobrecarga de conteúdos exigidos pela escola em uma semana de provas, prejudicando o desempenho do aluno. $\mathrm{S}_{1}$ demonstra claramente as dificuldades do sistema de avaliação adotado pela escola e suas consequências:

[...] a gente não tinha descanso, era prova seguida de prova. Não dava nem para respirar! E como eu sempre ficava de recuperação, eram mais provas ainda! [...] A gente não tinha nem tempo pra se preparar para uma recuperação, o que adiantava fazer então? Nossa, e eu ficava muito cansada, viu?

Em relação a essa questão, $\mathrm{S}_{3}$ revela como se sentia diante da semana de provas: "A gente ficava naquela ansiedade, sabe? Naquele nervosismo [...] principalmente quando tinha prova de Física [...] era uma angústia! [...].

$\mathrm{S}_{4}$ apresenta uma visão crítica desse sistema na medida em que faz referência ao ensino balizado no vestibular: "O sistema é muito puxado!... É muito conteúdo que os professores precisam dar. É que é tudo voltado pro vestibular, né? Mas por mais que você estude pra não acumular matéria, chega uma hora que acaba acumulando!"

De acordo com os relatos, se os professores dessem uma prova, assim que terminassem um conteúdo, os alunos teriam mais chances de ter sucesso, pois a matéria não estaria acumulada.

\section{Núcleo 5 Feed-back punitivo}

Este núcleo é composto pelos relatos que retratam posturas e atitudes de alguns professores diante da classe, no momento da devolução das avaliações, reprimindo e humilhando os alunos que não foram bem.

Mesmo que este núcleo não compreenda relatos de todos os participantes, podese afirmar que o feed back punitivo é uma das situações que mais potencializam a aversão dos alunos. Para exemplificar, recorre-se a $\mathrm{S}_{4}$ :

Quando ele (professor) ia entregar alguma prova, a hora que ele chamava o meu nome, ele balançava a cabeça assim (negativamente), tipo: 'essa ai é uma burra mesmo!'. 
Nossa, aquilo me dava uma raiva! Caramba, ele não fazia isso com ninguém, só comigo! E fazia pra classe inteira ver mesmo! Ele olhava bem na minha cara e ainda falava: 'Que vergonha!'. Me humilhava mesmo!

$\mathrm{S}_{5}$ também comenta sobre esse fato:

0 que eu não gostava que ela (professora) fazia é que na hora de entregar as provas, ela chamava o nome da pessoa e fazia um comentário. Se a pessoa tivesse ido bem, ela falava parabéns. Mas se a pessoa tivesse ido mal, ela escorraçava na frente de toda classe! Isso era muito ruim!

De acordo com as verbalizações de $S_{2}$ é possivel destacar uma outra forma de feed back punitivo:

Ela (professora) dava tudo errado pra mim! Eu pegava as minhas provas e só via um monte de ' $x$ ' vermelho, não tinha um certinho pra contar a história [...] Eu tenho certeza que na hora que ela pegava a prova e via que era minha, ela pensava: Ih, essa é do $\mathrm{S}_{2}$, aquele burro, não vou nem dar muita atenção pra não perder meu tempo [...].

Este participante deduz que a professora corrigia suas provas de forma preconceituosa, uma vez que nada era considerado.

\section{Núcleo 6 Recuperação punitiva}

Neste núcleo 6, encontram-se relatos de sujeitos que vivenciaram situações de recuperação que também tiveram efeitos aversivos para os alunos. Nessas recuperações, os alunos deparavam-se com uma prova bem mais difícil que a anterior, com exercícios mais complexos que os da prova anterior. $\mathrm{S}_{1}$ exemplifica bem essa situação: "Na prova de recuperação dele (professor) era a mesma coisa, só caía os exercícios mais difíceis, aqueles que a classe inteira ficou com dúvida. E aí, todo mundo se ferrava!"

$\mathrm{S}_{5}$ também comenta sobre essa questão:

Era a D. (professora) mesma que elaborava as provas, tanto a prova normal quanto a prova de recuperação. Só que ela pegava bem mais pesado nas provas de recuperação e daí eu dançava! Acho que ela fazia pra sacanear quem tivesse ficado de recuperação $\left(\mathrm{S}_{5}\right)$.

$\mathrm{S}_{3}$ comenta que achava injusto o sistema de notas das provas de recuperação:

[...] a prova da recuperação era bem mais fácil que as provas normais. Mas uma coisa era errada, mesmo que você tirasse 10 na recuperação, você ficava com 5 na nota final. 
0 máximo de nota que você conseguia se você fosse pra recuperação era 5 [...] É muito injusto!

Segundo os relatos verbais de $S_{3^{\prime}}$ o professor, através da recuperação, não reconhecia o progresso do aluno uma vez que a nota máxima que este pode conseguir é cinco. Esse fato também evidencia a recuperação como uma prática punitiva e incoerente.

\section{Núcleo 7 Preconceito do professor}

0 presente núcleo foi estruturado a partir de verbalizações que retratam atitudes de professores, diante do insucesso de seus alunos, consideradas como preconceituosas frente a eles, no sentido de não acreditarem em sua capacidade de recuperação. $\mathrm{S}_{4}$ conta como o preconceito, por parte de seu professor, tornou-se evidente para ela:

Eu tinha uma amiga que conversava com ele (professor) direto, e ela me disse que ele falou pra ela que não suportava olhar na minha cara, que não gostava de mim de jeito nenhum! Falou que eu era uma burra e que nunca iria entender o que ele tava explicando, que era perda de tempo tentar ensinar alguma coisa pra mim, que explicar pra mim ou pro nada era a mesma coisa [...] Nossa, eu fiquei arrasada quando ela veio contar isso pra mim [...]

As atitudes desse professor fizeram com que $\mathrm{S}_{4}$ desistisse de pedir auxilio durante as aulas, ampliando, consequentemente, sua dificuldade.

Assim como $\mathrm{S}_{4^{\prime}} \mathrm{S}_{2}$ também relata sobre as consequências do modo de agir de sua professora:

Eu nunca tirava dúvidas com ela (professora) porque eu tinha medo de perguntar e achava que tudo o que eu fazia era errado. Mas isso porque ela sempre agiu assim, como se tudo que viesse de mim fosse errado. Daí eu chegava em casa e pedia pro meu pai ou pra minha mãe me explicar.

Ainda sobre esse tema, $S_{5}$ conta que sua professora não acreditava que ele pudesse estar superando suas dificuldades. Para ela, que já havia desenvolvido um preconceito em relação a ele, era inadmissivel que ele pudesse, de fato, estar tendo sucesso em sua disciplina: "Ela não admitia que eu pudesse estar conseguindo recuperar. Dai, em dia de prova, ela pegava a minha carteira e colocava grudada na lousa, longe de todo mundo só pra garantir que eu não tava colando mesmo" $\left(\mathrm{S}_{5}\right)$.

\section{Núcleo 8 Plantão: auxílio que não auxilia}

0 núcleo 8 compreende os relatos sobre os plantões de dúvidas, que eram realizados fora do horário de aula, mas que, na prática, não correspondem, de fato, a um auxilio, uma vez que a maioria dos alunos voltava para casa com as mesmas dúvidas que tinham. 
Através das verbalizações de $S_{1}$ fica evidente que os plantões não correspondem a um auxilio e, consequentemente, os alunos não conseguem sanar suas dúvidas. Durante as aulas, os professores não tiram dúvidas devido ao pouco tempo disponivel para ensinar o conteúdo estipulado pelo calendário: "Os plantões também nem adiantavam muita coisa, muitas vezes nem era o professor que tirava as dúvidas [...] E ia muita gente nos plantões daí, na maioria das vezes, eu não conseguia tirar todas as minhas dúvidas".

Como a escola não era capaz de solucionar o problema das dúvidas dos alunos, estes tinham que buscar soluções fora dela. $\mathrm{S}_{1}$ conta como procurava tirar as dúvidas sobre a matéria: "[...] os plantões de dúvidas também não adiantavam muito e aí a gente tinha que procurar auxílio em outro lugar. É como eu te falei, muitas vezes a gente ia na casa do P. (colega de classe), que era inteligente, em vez de ir no plantão."

Assim como $\mathrm{S}_{1}, \mathrm{~S}_{3}$ aponta a deficiência dos plantões: "[...] aqueles plantões não adiantavam nada, até porque era outro professor [...] Aí, o professor do plantão explicava tudo diferente. Se você já não tava entendendo alguma coisa, você passava a não entender mais nada [...]".

\section{Núcleo 9 Ausência de feed-back}

Neste núcleo, estão presentes verbalizações que evidenciam situações em que os alunos não recebiam um retorno do professor sobre seu desempenho, mas somente eram informados sobre a nota que tinham tirado.

$\mathrm{S}_{1}$ relata que se sentia prejudicada, pois a correção das avaliações era desvalorizada pelos professores:

0 ruim desse professor é que ele sempre entregava as provas um dia antes da prova de recuperação e aí, sempre pegava a gente de surpresa [...] a gente queria saber onde a gente tinha errado, entende? 0 gabarito era só o resultado. Se a gente visse a prova um tempo antes, podia tirar nossas dúvidas. Só que ele não tava nem aí.

$\mathrm{S}_{2}$ também relata sobre a ausência de correção das provas com a classe. Além disso, ele infere sobre a falta de flexibilidade da professora diante da possibilidade de uma nova prova, devido a um grande número de notas baixas: "Outra coisa ruim das provas dela (professora) é que ela nunca dava um retorno. Ela não corrigia as provas com a gente, nem deixava a gente fazer outra prova sobre 0 assunto se a maioria da classe tivesse ido mal" $\left(\mathrm{S}_{2}\right)$.

\section{Núcleo 10 Avaliação como punição}

Este núcleo de significação reúne relatos verbais que caracterizam a avaliação como uma forma de punir os alunos, geralmente diante de situações julgadas como 
indisciplina pelo professor. $\mathrm{S}_{1}$ comenta que a classe prejudicava-se diante de uma prova surpresa, para punir alguns alunos que estavam fazendo bagunça:

Acho que o pior de tudo é que ele (professor) usava a prova para ameaçar os alunos, sabe? Sempre que a classe tava fazendo muito 'zona', ele mandava a gente pegar uma folha e fazer um exercício para nota. E esse exercício era sempre dos mais difíceis! $\mathrm{E}$ o pior é que quem não tava bagunçando se ferrava por causa dos outros. Não era justo!

$\mathrm{S}_{3}$ também relata casos em que o professor puniu a classe com uma avaliação:

Já aconteceu do professor chegar na classe e falar: 'Peguem uma folha em branco e anotem o que eu vou colocar na lousa porque hoje eu vou dar uns exercícios pra nota'. E aí, ele dava esses exercícios e depois dava uma nota... Só que todo mundo ia mal porque ele pegava a classe de surpresa [...] Não sei por que ele fazia isso. Não era com a intenção de ajudar porque isso só prejudicava a sala toda. A gente começou a reparar e percebemos que ele sempre vinha com esses exercícios pra nota depois de alguma aula em que a gente tinha bagunçado muito.

\section{Núcleo 11 Memorização sem sentido}

No presente núcleo de significação, a avaliação é percebida como uma prática que exige dos alunos apenas memorização, e não compreensão dos conteúdos estudados. $\mathrm{S}_{2}$ conta o que achava das avaliações que fazia: "[...] aquelas provas não avaliavam nada! Sabe aquelas perguntas que você só sabia se decorasse? Era uns detalhes que não tinha nada a ver. Parece que ela faz de propósito, só pro aluno ir mal mesmo. Eu reprovei esse ano".

$\mathrm{S}_{5}$, por sua vez, diz que, para o aluno ter sucesso na prova, ele tinha que decorar uma série de conceitos mesmo sem os compreender:

Com tanta coisa pra decorar, o que acontecia é que eu decorava só que não tinha a mínima idéia do que eu tava decorando. Tipo, eu não sabia como usar aqueles verbos em uma frase, sabe? E a gramática também, eu não sabia o porquê de usar aqueles auxiliares que nem o 'do' e o 'did'. Aí ficava confuso!

\section{Núcleo 12 Avaliação com um fim em si mesma}

Os relatos deste núcleo revelam que a avaliação é tida como uma prática com um fim em si mesma e não numa perspectiva diagnóstica: seu objetivo é classificar os alunos. $S_{2}$ demonstra essa dimensão da avaliação classificatória que vivenciou: "A gente tinha uma avaliação de cada matéria por bimestre, então eram quatro avaliações de uma mesma matéria por ano. Ou seja, se a gente fosse mal, já era, não tinha chance de recuperar. Só no bimestre que vem." 
$\mathrm{S}_{2}$ considera a prática de avaliação não como um processo mas com um fim em si mesma, visto que o aluno era classificado de acordo com a nota de uma única prova.

\section{Núcleo 130 melhor aluno como parâmetro}

Os relatos deste núcleo temático descrevem professores que tomam como parâmetro, para elaboração das avaliações, os alunos com melhores desempenhos.

De acordo com os relatos de $\mathrm{S}_{5}$, é possivel notar que os alunos que tinham dificuldades na matéria eram desconsiderados pela professora no momento da elaboração das avaliações e, consequentemente, eles acabavam sendo prejudicados:

As pessoas que faziam Inglês fora da escola, nessas escolas de idiomas, iam super bem nas provas. Eles achavam a prova super fácil, entendiam tudo. Daí, acho que a D. (professora) pensava que eles iam bem por causa das aulas dela. Tipo, acho que ela pensava que as aulas dela eram boas e que não tinham nada de errado. Muita gente fazia Inglês fora da escola, mas o pessoal que não fazia, que nem eu, não conseguia fazer a prova direito porque a gente não entendia muita coisa $\left(\mathrm{S}_{5}\right)$.

\section{Núcleo 14 Calendário burocratizado}

0 núcleo 14 apresenta relatos verbais descrevendo a situação de escolas que desenvolvem todo o seu processo de ensino em função de um calendário previamente definido, e as consequências desse fato.

$\mathrm{S}_{1}$ relata a sua visão diante do calendário instituído pela escola, durante todo 0 ano letivo. Ela observa que, com o calendário, os alunos sentiam-se abandonados pelos professores, que diziam que a função do calendário era informar os alunos e, portanto, essa não era mais sua função. $\mathrm{S}_{1}$ acrescenta sobre esse mesmo assunto: "Como a gente tinha o calendário de provas, o professor nem falava: olha, isso vai cair na prova. A gente tinha que olhar todo o calendário e ver todo o conteúdo que iria cair. A gente tinha tudo anotadinho".

\section{Núcleo 15 Situações que potencializam o efeito aversivo}

Neste núcleo, foram agrupados os relatos que descrevem situações que contribuíram para potencializar os efeitos aversivos das práticas de avaliação vivenciadas, por parte de professores e pais. 0 núcleo 15 está subdividido em dois subnúcleos , que serão apresentados a seguir.

\section{Subnúcleo 15.10 professor como um fator potencializador}

No presente subnúcleo, o professor é tido como um fator que contribuiu para o aumento do sentimento aversivo do aluno, em relação às práticas de avaliação 
adotadas e à própria disciplina. Essa potencialização da aversão, pelo professor, se dá através de diferentes formas de agir. Na maior parte das vezes, o mau relacionamento entre professor e aluno gera sentimentos de raiva, ódio e a sensação de desprezo e humilhação, por parte dos alunos.

Durante as entrevistas, alguns sujeitos relataram sobre as consequências do comportamento hostil do professor, em relação a eles ou, até mesmo, à classe:

Ele (professor) era muito grosso, ele respondia pro aluno! E se alguém tinha alguma dúvida ele era grosso, entendeu? Ele dava umas 'patadas' assim, sabe? Ele chamava até a gente de burro! Eram poucos os alunos que tinham coragem de falar com ele na sala de aula $\left(\mathrm{S}_{1}\right)$.

Ela (professora) era uma pessoa assim [...] muito brava dentro da sala de aula. Todo mundo tinha medo dela, entende? Então, a gente ficava até meio que com receio de fazer perguntas por causa do jeito dela $\left(\mathrm{S}_{2}\right)$.

$\mathrm{S}_{4}$ conta sobre uma situação em que foi reprimida pelo professor, diante da classe, que se tornou um divisor de águas na sua relação com ele:

Como eu já te disse, eu sentava na primeira carteira pra tentar entender o que o professor falava. E ele sempre falando, falando, falando, despejando a matéria [...] até que chegou um dia, eu chamei ele e falei: 'B., eu não to entendendo o que você ta falando! Dá pra você repetir pra mim?'. E aí ele me respondeu: 'Ah, mas como você não ta entendendo o que eu to falando? Você tem dificuldade em ouvir as pessoas? Você tem problema de audição? Deve ter, porque nas provas você nunca consegue fazer nada!'. E eu ainda respondi: 'Não é que eu não escuto o que você fala, eu não entendo o que você fala!'. Mas nessa hora a classe toda já tava gargalhando da piadinha dele. Nossa, me deu muita raiva! Ele foi completamente irônico! Desde esse dia a situação piorou porque eu já ia mal, já tinha dificuldade e ainda por cima passei a ter raiva do professor!

\section{Subnúcleo 15.2 A condição potencializadora do efeito aversivo em casa}

Neste subnúcleo, encontram-se relatos de $S_{2}$ que descrevem situações que potencializaram a aversão em relação à avaliação vivenciada, em casa, através da incompreensão dos pais que o agrediam devido às notas baixas:

Quando eu comecei a tirar notas baixas nas provas, meu pai começou a estudar comigo. E o meu pai é português, ele tem um jeito de lidar com essas situações meio agressivo [...] Se eu errava alguma coisa, ele batia em mim em casa, então, eu tinha 
que aprender ou aprender. Não tinha outra opção [...] Eu sabia que além de outra nota baixa, ainda ia ganhar uns tapas do meu pai. Isso, com certeza, também agravou toda situação.

$\mathrm{S}_{2}$ revela que essas experiências marcaram profundamente suas lembranças e geraram um sentimento de fracasso e impotência:

0 que ficou muito forte na minha memória também foram os tapas que eu tomei do meu pai naquele ano. Era muito duro porque eu não ia mal porque era vagabundo, eu ia mal porque eu não conseguia fazer as questões que estavam na prova. Meu pai até estudava comigo, mas na hora $H$, não ia.

\section{Sobre os dados apresentados}

Os dados acima apresentados focam questões relacionadas com o processo de mediação pedagógica desenvolvido pelo professor em sala de aula. É possível notar que as decisões que o professor toma, em relação às práticas de avaliação, certamente, produzem marcas afetivas e interferem na relação que se estabelece entre 0 aluno e o objeto de conhecimento em questão.

0 modelo de avaliação adotado em grande parte das escolas tem contribuído com os altos índices de fracasso escolar, representado pela repetência, evasão e, também, a exclusão interna do aluno. A avaliação ainda constitui um dos pontos nevrálgicos do nosso sistema de ensino, contribuindo para o desenvolvimento de sentimentos aversivos entre sujeito e objeto, gerando dramas pessoais que acabam por afetar a autoestima dos alunos. Isso justifica a importância de trabalhos que revelem os efeitos danosos do modelo tradicional de avaliação e apontem alternativas que valorizem condições favoráveis para a aprendizagem e o desenvolvimento do aluno.

A análise dos núcleos, aqui apresentados, revela diversos efeitos originados pelas práticas aversivas de avaliação vivenciadas pelos sujeitos. Em síntese, podem ser identificados quatro desses efeitos que merecem considerações especiais:

\section{1) Deterioração da relação sujeito-objeto}

São notáveis os efeitos aversivos da avaliação tradicional, dificultando sobremaneira o processo de vinculação entre sujeito e objeto. Pode-se identificar essa consequência nos relatos verbais dos sujeitos da pesquisa, agrupados no Núcleo Temático - Marcas aversivas e, mais especificamente, nos subnúcleos Perda da motivação para estudar e Deterioração da relação sujeito - objeto. De modo geral, os sujeitos revelaram a consequência mais lamentável da prática de avaliação vivenciada: a deterioração da relação sujeito-objeto. Como já foi abordado anteriormente, analisar a questão da afetividade em sala de aula significa analisar as condições oferecidas para que se estabeleçam os vínculos entre sujeito e objeto. De acordo com os relatos, é possivel inferir que uma condição aversiva oferecida aos alunos, no pro- 
cesso de avaliação, pode provocar o desenvolvimento do sentimento de profunda aversão do sujeito em relação ao objeto de conhecimento em questão.

Relembrando Luckesi (1984), a avaliação, na perspectiva do modelo tradicional, pode tornar-se um instrumento autoritário e frenador do desenvolvimento, possibilitando a uns o acesso ao saber e, a outros, a estagnação e até a evasão escolar.

É possível notar que os efeitos relatados no subnúcleo Perda da motivação para estudar parecem ser de curto a médio prazo, ou seja, são efeitos, praticamente, imediatos e podem ter curta duração. Já os efeitos relatados no subnúcleo Deterioração da relação sujeito-objeto parecem ser de médio a longo prazo, ou seja, são efeitos que podem permanecer posteriormente.

\section{2) Produção de estigmas}

Para Luckesi (1984), o modelo tradicional da avaliação escolar assume, como principal função do ato de avaliar, a classificação e não o diagnóstico. 0 julgamento de valor, que poderia ter a função de possibilitar uma nova tomada de decisão pedagógica, passa a ter a função estática de classificar o aluno de acordo com um padrão determinado; o ato de avaliar não constitui um momento para repensar a prática pedagógica, mas, sim, um meio de julgar o aluno, mantendo-se as condições de ensino inalteradas. Com a função classificatória, a avaliação não possibilita o avanço e o crescimento do aluno e do processo de ensino-aprendizagem, ao passo que, com a função diagnóstica, ela pode ser direcionada para esta finalidade, educacionalmente mais relevante.

Os dados sugerem que a avaliação classificatória produziu muitas consequências negativas, entre elas o preconceito e o estigma do aluno. Os núcleos Ausência de feed back e Avaliação com um fim em si mesma evidenciam que a função das práticas de avaliação adotadas era, basicamente, classificar os alunos em algum nível e, consequentemente, estigmatizá-los.

0 núcleo Ausência de feed back também evidencia a prática de avaliação como um fim em si mesma, visto que os resultados das provas eram ignorados, não sendo utilizados a favor do aluno, ou seja, no sentido de rever e alterar as condições de ensino.

Os subnúcleos Sentimento de incapacidade e Frustração e Exclusão também apontam sérios efeitos das práticas de avaliação adotadas, que afetam a autoestima dos alunos, contribuindo para o desenvolvimento de sentimentos de incapacidade, de frustração e de exclusão.É possivel inferir, a partir das verbalizações, que esses sentimentos não foram efêmeros; ao contrário, os dados sugerem que acompanharam e marcaram a vida escolar dos alunos até aquele momento.

No subnúcleo 0 professor como um fator potenciliador, o professor é situado como um fator que pode contribuir para o aumento dos sentimentos aversivos do 
aluno, em relação às práticas de avaliação adotadas. Essa potencialização ocorre através de diferentes formas, o que ratifica o comportamento do professor como um dos determinantes para a manutenção dos estigmas dos alunos. Relataram-se situações de negligência e implicância, por parte dos docentes. 0 mau relacionamento entre professor e aluno pode gerar sentimentos de raiva, ódio e as sensações de desprezo e humilhação, por parte dos alunos, como sugerem os relatos.

\section{3) Instrumento de poder nas mãos do professor}

A partir das práticas tradicionais relatadas, percebe-se que a avaliação pode desempenhar um papel disciplinador nas mãos do professor. Daí decorrem manifestações constantes do autoritarismo, podendo chegar à sua exacerbação.

Conforme Luckesi (1984), um exemplo do uso autoritário do professor das práticas da avaliação é a definição do que será considerado como relevante ou irrelevante, em função exclusivamente do seu arbítrio pessoal ou, o que é pior, do seu estado psicológico de momento.

Como exemplo, os sujeitos desta pesquisa retrataram a situação da avaliação como uma armadilha criada pelos professores, na medida em que cobram, intencionalmente, na prova, conhecimentos mais complexos, que não se relacionam com as práticas desenvolvidas na sala de aula.

Alguns sujeitos vivenciaram, também, situações de recuperação punitiva. Nessas recuperações, os alunos deparavam-se com uma prova bem mais difícil que a anterior, com exercícios mais complexos que os da prova anterior. Ou seja, uma prova que teria como objetivo principal ajudar os alunos a se recuperarem, passa a ser mais uma armadilha. Nessas práticas relatadas, fica evidente que a avaliação não é utilizada a favor do aluno, uma vez que seu objetivo não é ajudá-los; ao contrário, essas práticas de avaliação acabam prejudicando-os, como os relatos claramente sugerem.

Outros exemplos do uso autoritário, pelo professor, das práticas de avaliação evidenciam-se através do controle de corpos e do feed back punitivo. Através de suas posturas, na situação de avaliação, os professores demonstram grande preocupação com o controle das condições físicas dos alunos e do ambiente. Os dados indicam que o dia de prova transforma-se num triste ritual devido às inúmeras obrigações exigidas pelos professores. No entanto, essas exigências acabam alimentando o medo e a ansiedade dos alunos em relação à avaliação e, por extensão, à própria disciplina em questão..

A relação professor-aluno torna-se, muitas vezes, inamistosa pela relação de poder que se instaura em seu interior - no caso, marcada por um sentimento de desconfiança para com o aluno, assumido aprioristicamente. De acordo com Maciel (2003, p. 19): 
Se, de um lado, a escola usa a avaliação como instrumento de poder e de controle do aluno, por outro, o aluno acaba desenvolvendo estratégias de sobrevivência e criando um 'contra-poder' estabelecendo uma relação utilitarista com o saber e com o outro; conseguir nota a qualquer custo, mesmo que através de 'cola' (que é mais comum do que se imagina): seja material (escritos em papéis, borracha, carteira, etc.) ou mental (memorização mecânica). De qualquer maneira, o que se verifica frequentemente é que não há correlação entre nota e a qualidade da aprendizagem. Ou seja, o aluno acaba descobrindo o jogo da escola e encontra formas de resistência e enfrentamento.

Os relatos dos alunos que vivenciaram feed back punitivos retratam as atitudes de professores diante da classe, no momento da devolução das avaliações, reprimindo e humilhando os alunos que não foram bem. Pode-se afirmar que o núcleo Feed back punitivo apresenta dramáticos relatos de situações que mais potencializam a aversão dos alunos - eles se sentem invadidos, humilhados e totalmente constrangidos.

Outro uso autoritário da avaliação é a sua transformação em mecanismo disciplinador de condutas sociais. Uma prática frequente no meio escolar é a utilização do poder e do veredicto da avaliação para ameaçar os alunos, como os dados sugerem.

Desenvolvidas dessa forma, as práticas de avaliação transformam-se em um instrumento de poder nas mãos do professor. Alguns sujeitos caracterizaram as práticas de avaliação vivenciadas como formas de punição dos alunos, geralmente diante de situações consideradas como de indisciplina. Esses sujeitos comentam o quanto a classe prejudicava-se com as provas-surpresas e inferem que o objetivo do professor, com esse tipo de prova, era apenas punir a classe.

A avaliação, utilizada como um instrumento de poder pelo professor, torna-se, consequentemente, um instrumento de ameaça, gerador de sentimentos negativos, o que explica que os dias de avaliação podem causar grande sofrimento na vida dos alunos.

O subnúcleo "Medo e ansiedade" agrupa os relatos que revelam os sentimentos de medo e ansiedade gerados pelo dia da avaliação. Observa-se que a avaliação, na perspectiva tradicional, torna-se uma prática que provoca intensos sentimentos, a ponto de prejudicar a qualidade de vida dos alunos.

\section{4) 0 processo de ensino em função do vestibular}

De acordo com os sujeitos participantes, o fato de as escolas desenvolverem as práticas pedagógicas explicitamente com base no vestibular, também contribuiu com a potencialização da aversão. Isto porque os alunos sentem-se limitados e pressionados, visto que eles têm de aprender muitos conteúdos em um espaço de tempo predeterminado e restrito. 
Grande parte dos sujeitos comentou sobre o ritmo alucinante da semana de provas. Eles contam que a sobrecarga de conteúdos exigidos pela escola, em apenas uma semana, prejudica o seu desempenho. Esses sujeitos relatam que, que se os professores ministrassem as provas no final dos conteúdos, eles alunos - teriam a oportunidade de se preparar melhor para as provas. Devido a esse sistema de avaliação, situações geradoras de medo e ansiedade, em relação à avaliação, acabam aumentando e gerando mais aversão à situação escolar e a determinados objetos de conhecimento.

\section{Considerações finais}

Os dados apresentados neste trabalho, obviamente, não dão conta de toda a problemática da avaliação escolar em nosso sistema de ensino, da mesma forma que não discutem as mudanças recentes da política educacional na área: essas questões exigem outras pesquisas e análises. 0 objetivo presente é mais limitado, porém não menos relevante: procura-se demonstrar que as práticas tradicionais de avaliação escolar podem ter efeitos deletérios na relação que se estabelece entre os alunos e os objetos de conhecimento em questão. A partir dos relatos dos sujeitos participantes, é possivel reafirmar que a avaliação constitui-se em um dos pontos nevrálgicos do nosso sistema de ensino, podendo afetar profundamente a qualidade da vida escolar dos alunos. Sendo assim, dentre as decisões pedagógicas assumidas pelos docentes no planejamento do ensino, a avaliação merece uma atenção especial, como foi evidenciado pelos relatos dos jovens aqui apresentados.

Sendo uma importante dimensão da mediação pedagógica do professor, as práticas de avaliação envolvem, sensivelmente, a dimensão afetiva, não se restringindo apenas aos aspectos cognitivos. Desta forma, devem ser planejadas e desenvolvidas como um instrumento sempre a favor do aluno e do seu processo de apropriação do conhecimento.

Os dados sugerem que o processo de avaliação da aprendizagem em sala de aula é um dos principais fatores determinantes da qualidade dos vínculos que se estabelecerão entre o sujeito e os objetos do conhecimento. Além disso, uma mediação positivamente afetiva envolve a melhora da autoestima dos alunos, favorecendo a autonomia e fortalecendo a confiança em suas capacidades e decisões - isto porque ela favorece a aprendizagem do aluno, ou seja, ela favorece o seu sucesso escolar.

Segundo Leite e Tassoni (2002, p. 17), "pode-se afirmar, sem exageros, que a qualidade da mediação pedagógica, em muitos casos, determina toda a história futura da relação entre o aluno e um determinado conteúdo ou prática desenvolvida na escola. Tal história também é essencialmente afetiva". 
De acordo com Luckesi (1984), em função de estarem no bojo de uma pedagogia que traduz as aspirações de uma sociedade conservadora, as práticas tradicionais de avaliação da aprendizagem escolar podem exacerbar a autoridade e oprimir o educando, impedindo o seu crescimento e transformação. Segundo o autor, para romper com esse processo, é necessário romper com a ideologia liberal e com a pedagogia que a traduz. Para que a avaliação educacional escolar assuma o seu verdadeiro papel de instrumento de diagnóstico para o crescimento do aluno, ela terá que se situar e estar a serviço de uma pedagogia que esteja preocupada com a transformação social e não com a sua conservação.

A avaliação diagnóstica, como já apresentada, representa uma importante alternativa diante dessa situação, visto que supõe que o ato de avaliar deve implicar decisões assumidas sempre a favor do aluno, sendo os seus resultados utilizados no sentido de permitir ao professor rever e alterar as condições de ensino, visando ao aprimoramento do processo de apropriação do conhecimento pelo aluno.

Sendo assim, é importante ressaltar a necessidade do resgate da avaliação como função diagnóstica. Através dessa função, a avaliação é planejada e desenvolvida como uma situação de reflexão, preferencialmente envolvendo o conjunto dos educadores da escola, no sentido de buscar não só o avanço cognitivo dos alunos, mas propiciar as condições afetivas que contribuam para o estabelecimento de vínculos positivos entre os alunos e os conteúdos escolares. Com a função diagnóstica, a avaliação pode auxiliar o progresso e o crescimento do aluno, através do aprimoramento das condições de ensino.

Com base nos relatos da presente pesquisa, torna-se evidente a necessidade de se reverem e se alterarem as práticas de avaliação adotadas tradicionalmente. Formas alternativas, como a avaliação diagnóstica aqui discutida, devem ser implementadas, compatíveis com uma pedagogia inclusiva, direcionada para o processo de transformação social e para o crescimento e desenvolvimento integral dos alunos.

\section{Referências}

FREITAS, L. C. Ciclos, seriação e avaliação: confronto de lógicas. São Paulo: Moderna, 2003. (Coleção cotidiano escolar).

GALVÃO, I. Henri Wallon: uma concepção dialética do desenvolvimento infantil. Petrópolis: Vozes, 2001.

KAGER, S. As dimensões afetivas no processo de avaliação. In: LEITE, S. A. S. (Org). Afetividade e práticas pedagógicas. São Paulo: Casa do Psicólogo, 2006. 
LEITE, S. A. S. (Org.). Afetividade e práticas pedagógicas. São Paulo: Casa do Psicólogo, 2006.

LEITE, S. A. S.; TASSONI, E. C. M. A afetividade em sala de aula: as condições de ensino e a mediação do professor. In: AZZI, R. G.; SADALLA, A. M. F. A. (Org.). Psicologia e formação docente: desafios e conversas. São Paulo: Casa do Psicólogo, 2002.

LUCKESI, C. C. Avaliação educacional escolar: para além do autoritarismo. Tecnologia Educacional, Rio de Janeiro, n. 61, 1984.

MACIEL, D. M. A avaliação no processo ensino-aprendizagem de matemática no ensino médio: uma abordagem formativa sócio-cognitiva. 2003. Dissertação (Mestrado em Educação) - Faculdade de Educação, Universidade Estadual de Campinas, Campinas, SP, 2003.

WALLON, H. A evolução psicológica da criança. Lisboa: Edições 70, 1968. . Do acto ao pensamento. Lisboa: Moraes, 1978. . As origens do caráter na criança. São Paulo: Difusão Européia do Livro, 1971. VYGOTSKY, L. S. A formação social da mente. São Paulo: Martins Fontes, 1984.

Recebido em: 02/10/2007

Aceito para publicação em: 04/02/2009 